\title{
Reduce the allocated training time per head in an apparel company by using Arduino technology
}

\author{
The project of Dancing Module Simulator (DMS)
}

\author{
O.V Jayasinghe (Author) \\ Department of Electrical \& Electronic Engineering \\ SLIIT - Sri Lanka Institute of Information Technology \\ Malabe, Sri Lanka \\ oshadavidu@gmail.com \\ G.A.P.R Perera (Author) \\ Department of Aeronautical Engineering \\ General Sir John Kotelawala Defence University \\ Ratmalana, Sri Lanka \\ Pramith.27@gmail.com \\ DOI: $10.31364 / S C I R J / v 7.11 .2019 . P 0119601$ \\ http://dx.doi.org/10.31364/SCIRJ/v7.i1.2019.P0119601
}

\begin{abstract}
Simulator training for industries has been developed during the last decade in almost all the cooperate sectors around the globe. Enhance the time consuming and reducing resource needs for training purposes were expected from the simulator trainings. Currently approximately five industries in Sri Lanka entitled to the field of digital trainings such as aviation, military, marine, railway and medical. Apparel industry is one of the most developed industries in Sri Lanka and giant apparel exporters have being operating with large number of employees. The complexity of the operations inside an apparel company gets increase frequently due to the requirements coming from the international market. Design a suitable module for trainings of newly recruited employees in apparel industry was raised as the time allocation for trainings was identified as critical figure in the process. Develop the quality of the training with the extended support of digital programming is the key expectation from such a project. Arduino as a modern programming tool use for electro-mechanical interfaces can be used successfully to design a well mapped training simulator for apparel industry. Enrich the user friendly training environment with less amount of resource allocating was set as the nominated outcomes from the project. Training time period set per head in the initial training process has been focused to reduce in significant figure in terms of save the time, financial resources and the other factors linked to the training procedure.
\end{abstract}

Index Terms- Simulator, Arduino Technology, Apparel Industry

\section{INTRODUCTION}

Apparel industry in Sri Lanka has been identified as one of the major business sectors which impacted a lot for the development of the national economic growth. Several companies have established in the country to make a manufacturing environment for apparel products in order to supply the garments to the international market. The government of Sri Lanka was tabled a specific act of Free Trade Zones and published an extra special gazette mentioned the specific advantages and reliefs which can be obtained by the companies who invested on these zones. Several government taxes and levy were waved off for these companies. Also these employers have offered thousands of job opportunities for local youths who were looking for suitable careers. Most of the companies who currently operate inside these zones are apparel exporters. Few companies are there who do industrial manufacturing such as machinery equipment, rubber processing, industrial tool manufacturing and marine equipment manufacturing. After imposed the government act of Free Trade Zone (FTZ) concept in 1977, Sri Lanka has entered to the international market in terms of providing standardized products under world class brand names. Apparel industry is one of the major trade sectors which established largely with global customers. Sri Lanka Board of Investment also known as BOI has established several Export Processing Zones around the country to encourage local and multinational companies to invest there in order to join with the global economy. Apparel exporting has started in those zones and introduced a new trend of quality and standard Sri Lankan apparel to the world market. It marked a remarkable name for the best quality garments in front of the name "Made in Sri Lanka". XYZ Holdings came into this industry such a competitive corporate background like this and made a huge name in the industry as a giant.

Man power is the major factor which is needed to be driven the entire mechanism of the apparel company towards its financial goals. According to the practical situation inside the Free Trade Zones (FTZ) around the country, lack of man power is the most critical matter which all the companies who operate in Sri Lanka have faced. Due to the continuous absenteeism reporting of employees, companies operated in Free Trade Zones have to recruit new members in every quarters of the year. The time allocated for training practices is fixed as average of 68 days. The said time duration will be changed according to the operational background and the nature of the business of the company. Reducing the mentioned time slot will be generated a vast advantage for any employer as they can save more time, resources and man hours. Enlist 
new members to the main production flow with in a shorter time will be a huge win over the prevailing situation.

The respective company selected to this project is operating in Sri Lanka as a group of company who manufacturing many apparel products since 1987. XYZ Apparel Company is a holding company who is functioning as a group of company. All the cluster companies do the apparel related manufacturing too and some of them are supportive bodies. XYZ Apparel Company has started her journey in 1987 Panadura as a small apparel garments Production Company consists with 30 employees for their operations. The apparel products they manufactured at this premises were ladies lingerie garments. At this initial step, their buyers were Malaysia and England. Main brands they have handled at this stage were Victoria's Secret and Mark \& Spencer. They have developed and finished ladies brassieres, panties, briefs and sports bras at this factory. The founder of XYZ Apparel Company Mr. MA has signed few trade agreements with his buyers who do their businesses in European region. He maintained his company with the expected quality by the foreign customers. Due to the high quality of the products produced by XYZ Apparel Company, the earned customers' trust and managed to obtain further orders from them. Soon after the initial company completed five years of the business journey, they have signed trade agreements with world class brands such as Nike, GAP, LBI and Triumph. The company was expanded up to 345 employees during the first five years of the company. After that XYZ Apparel Company has entered into the Biyagama Free Trade Zone with its newer cluster with more than 50 employees. This was their second business cluster of the group.

At the end of 1995 the XYZ Apparel Company was established 5 business clusters in Biyagama, Katunayake and Koggala including their first company at Panadura. At this time they have entered into the manufacturing of sports wears. Their main customer was Nike and few other international giant brands also were joined with them. The company has earned a good trustworthiness and reputation as they have completed the orders with the highest possible quality. Within first ten years of the company it has opened twelve business clusters around the country and provided careers opportunities for more than 2500 local employees. At this stage of the company, two brothers of the founder wee joined with the company as stake holders.

With this great partnership the company was got more strong and opened another five business clusters. They have entered to the swim wears, sports wears including athletic suits, men's underwear's and fabric manufacturing industries. Many countries around the world have handed over their orders of design their official national kits of athletic and rugby to XYZ Apparel Company due to their high reputation. Star level athletes and swimmers recommended the company and it was built up the highest ever marketing promotion for XYZ Apparel Company. Nike Sports Cooperation was handed over the order to design and create their order for national athletic kit for United States athletes for Olympic Games to XYZ Apparel Company. New Zealand national rugby team, United Kingdom national rugby team and Ecuador national rugby teams have submitted their orders to the XYZ Apparel Company too. Super star soccer clubs such as Manchester United and Everton have signed trade agreements with the company to design their play kits. This popularity was earned a huge honor to the company and helped a lot to mark the company's name high in front of the global apparel industry. With this rapid progress of the company they have entered to the research and development sector of the fabrics and other materials which highly used for manufacturing the finished garments. At the end of year 2016 the XYZ Apparel Company has more than 37 business clusters with more than 95000 employees work under their name.

Table 1: Main Products and Customers

\begin{tabular}{|c|c|}
\hline Product & Customer \\
\hline \multirow{10}{*}{ Molded Bra Cups } & Victoria's Secret \\
\hline & LBI \\
\hline & Nike \\
\hline & $\mathrm{H} \& \mathrm{M}$ \\
\hline & $\mathrm{M} \& \mathrm{~S}$ \\
\hline & Victoria's Secret -Pink \\
\hline & GAP \\
\hline & Lulu Lemon \\
\hline & Triumphs \\
\hline & Corsina \\
\hline \multirow{2}{*}{$\begin{array}{c}\text { Sports Pants / Track Kits } \\
\text { (Unisex) }\end{array}$} & $2 \mathrm{XU}$ \\
\hline & Nike \\
\hline \multirow{2}{*}{$\begin{array}{c}\text { Impact Protection Units for } \\
\text { Rugby }\end{array}$} & Rhino \\
\hline & \\
\hline \multirow{3}{*}{ Ladies Panties / Briefs } & GAP \\
\hline & Victoria's Secret \\
\hline & CK \\
\hline
\end{tabular}

\section{THE DANCING MODULE USE IN PRODUCTION}

The XYZ apparel company has introduced a specific production module called The Dancing Module in order to increase the productivity of the production lines. This concept was originally imposed as a project of lean manufacturing and $5 \mathrm{~S}$ concepts of the company. Mainly they have introduced this module to their major production molded bra cups. The dancing module concept consists of three operations Panel Preparation, Molding Operation and Trimming. A one worker will be allocated for all these three functions in terms of archiving the production targets by reducing the Small Minute Value (SMV) allocated for production units. The employee who involve with dancing module must be well trained and skilful to carry out these three operations with accepted quality levels. Generally the training school of the company has been allocated 62 working days for the trainings to develop the skill level of a new employee.

Figure 1: The Dancing Module

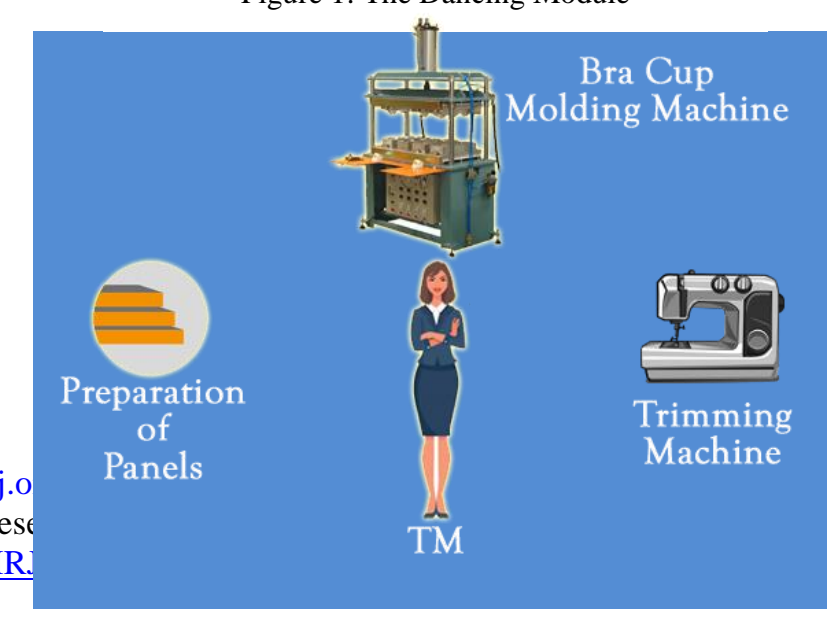




\section{A. Panel Preparation}

The panel preparation is the first step of the dancing module and the panels should be completely dust free before it entered to the bra cup molding machine. Foam panel will be cleaned by using a sticky roller and the worker must be followed the standard hand movements to do the cleaning part. The cleaning roll should be hardly moving on the panel from top to bottom in three times. After then the same movement and the pressure should be applied to the panel in right to left direction. Skill of the worker must be developed up to a better level in order to apply the defined pressure. During the initial training the worker has undergone 15 days training for panel cleaning.

Figure 2: Panel preparation process

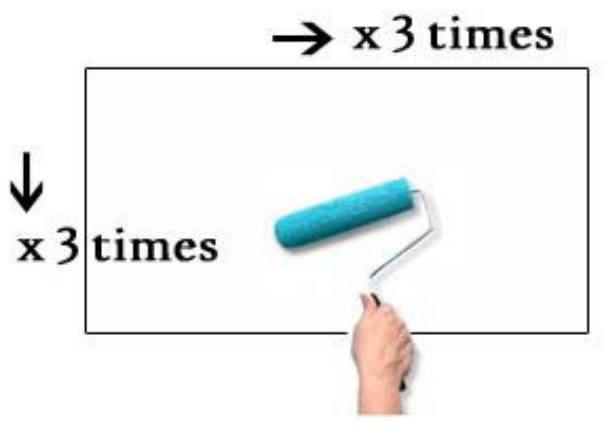

\section{B. Bra Cup Molding Operation}

Bra cup molding machine is the next operation of the dancing module. The molding machine is essential equipment for molded bra cup manufacturing which is working with the principles of thermodynamics. Heating temperature can be adjusted with the time in seconds. The molds created from pure aluminium at $\mathrm{CNC}$ workshop will be attached and align properly to the molding machine. After the expected heat achieved by the machine, the selected panel can be loaded in between the male and female molds. The compression begins between male and female molds the panel will be kept for given time for create the bra cup with appropriate features. The actuators fitted to the molding machine are working with the 6 bar pressure pneumatic supply. The skills of the operator must be at a better level in order to prevent the accidents and injuries of the molding operation. The knowledge of the heating and timing adjusting will also be counted as a compulsory skill which should developed in operator. During the initial training each trainee have to undergo 25 days training for molding operation.

\section{Trimming Operation}

Trimming the molded bra cup is the next operation of the dancing module. The worker must be well trained for this operation as it identified the most critical part of the production procedure. Molded bra cup should trim first from the outer engrave lines of the panel. Secondly the engrave lines of the bra cup must be trimmed sharply without harming to the inner cup area. During the initial training process more than 15 days will be given to trimming training.

\section{THE TRAINING PROCESS CURRENTLY IN USE}

The current training procedures for newly recruited employees have been defined by the respective training department and human resource management department. Training practices was designed to develop the skill levels of the employees. The respective skill level must be reached at the end of the training session after 62 days. At the end of the given period trainee must be ready to start his/her career in production lines. Maintain the standard cadre in the production lines is the main expectation of the company and the training process must be designed to align with this general vision. The current time allocated for initial training is the optimum level nominated by the training school management. Any improvements to reduce the time period for training will be an advantage for the company as it will make the process of new member allocation to the production lines faster than before. Below given the figures of training process currently observed by the training school management.

Table 2: Allocated time table for initial training

\begin{tabular}{|c|c|c|}
\hline & Phase & Time slot allocation \\
\hline 1 & Introduction program & 2 days \\
\hline 2 & Panel preparation training & 15 days \\
\hline 3 & Molding operation training & 25 days \\
\hline 4 & $\begin{array}{c}\text { Trimming operation } \\
\text { training }\end{array}$ & 20 days \\
\hline \multicolumn{2}{|r|}{ Total days } & 62 days \\
\hline
\end{tabular}

According to the company's annual human resource management report, 345 employees have been released for production lines by the training school during last two years. But the required cadre by the production control department was 400 workers. Due to the resource management, financial limitations and time consuming for training program the training school were not able to fulfill the required cadre. The need for a new project which will be reduced the allocated time was occurred as a result of this matter appeared.

Table 3: Training figures in last two years

\begin{tabular}{|c|l|l|l|}
\hline Year & No of workers trained & $\begin{array}{c}\text { Days per } \\
\text { training session }\end{array}$ & Cost per head \\
\hline 2017 & 152 & 62 & 3750 LKR \\
\hline 2018 & 193 & 63 & 3975 LKR \\
\hline
\end{tabular}

The figures shown above tables were recorded by the training school and the total budget spent for those two programs have been exceeded the allocated financial resources by the company. Some of the employees released to the production lines have left the company before the completion of one year. This matter also reported as a big issue which led company's financial capabilities into a question. 


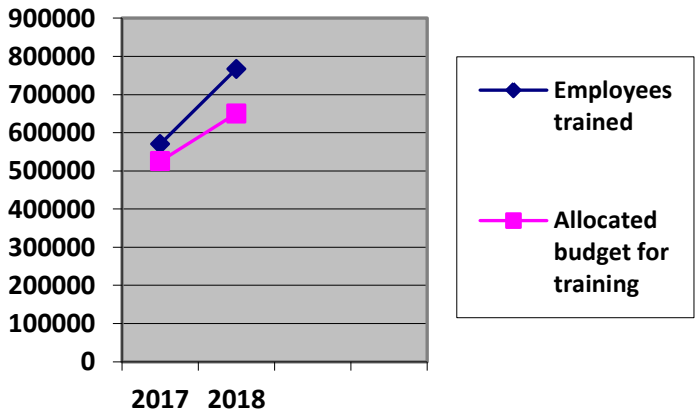

Chart 1: Training budget plan

\section{A. Requirement of new training procedure}

In order to reduce the time allocation for initial training phases, the company required a scientific support of digital technology means of supportive tool for training practices. Financial sources of the company planned to be reduced by introducing a new method for trainings. Allocated budget per head for initial training should not be exceeded by a new system and it should be user friendly and reliable too. The main expected outcome of the initial training is to create an employee who is enrich full with required skills defined for production level.

International customers of the XYZ apparel company have been agreed to some conditions to be maintained in their partner companies around the world. In order to maintain this standard practices and directions given by the customers, the company should be considered about the quality of the training provided to their employees. Any digital procedures means any kind of supportive systems for the training sessions must be designed not to violate the standard procedures.

\section{B. Introduction to simulator training}

Simulator training can be defined as the procedure of the involvement of digital technology as an virtual user interface in order to create a realistic working environment. Most of time simulator trainings have been used for a situation where the real experience of the respective machine or incident is quite difficult at the beginning phases. The critical level of the machines, safety concerning, expensive for training and other reasons have been considered by the employer when they plan to start a training process for their new members. At this point simulator trainings is the most important part for conducting the training with low cost per head. Below mentioned factors are the benefits of simulator training for any kind of employer.

1. Time consuming - simulator training will reduce the allocated time for training significantly.

2. Low cost - simulator training will reduce the cost per head allocated for training.

3. Safety concern - in some cases initial training may be really serious for a trainee. Simulator training will help to understand the basics and eliminated the risk of the trainee.

4. Data handling - simulator training provide a proper room for analysis the statistics of the trainee to evaluate.
5. High success rate - initial simulator training will create high skillful trainees than traditional training practices.

\section{METHODOLOGY}

\section{A. Arduino programming interface}

The uses of Arduino have not limited too few boundaries in electronic and mechanical concept. It is considered as ElectroMechanical microchip interface which can be used to run functional programs on it. Arduino is a electronic circuit board which consists of main microchip for programming loading and other electronic equipment such as capacitors, resistors and transistors. The multifunction capability of Arduino have achieved by using multiple operational ICs run parallel with the microchip inside. Arduino can be used with the interconnection of Raspberry $\mathrm{Pi}$ and ARM programming technologies.

Arduino is a microchip programming hardware interface use in modern electronic programming industry. Furthermore it can be identified as the most popular programming hardware interface which has been used widely in many industries. Mainly it consists of multifunctional microchip with on-built logical interface. Electronic devices and other supportive sensor modules can be bridged with the Arduino board. Arduino can be used as Arduino UNO, Mega or other extensions. The technology is widely used in electromechanical innovations. The respective programming interface coupled with the computer code writing working module called Arduino IDE. The user can be loaded instructions means sketch of the coding through this software interface. The basic Arduino coding can be done using $\mathrm{C}++$ programming language. In this project, the user interface was Arduino UNO. Extensions will be worked as developing platform of basic technology and the results can be monitored using a computer interface.

\section{B. Steps for Arduino programming}

Hardware Attachment: The other electronic tools, equipment or sensors must be attached to the Arduino board properly. For the testing prototype purposes a bread board can be used to interconnect the electronic equipment with the Arduino interface. Close consideration must be maintained during the hardware interconnecting step as all the connections needed to be linked properly to the board.

Sketching: The programming part of Arduino called "Sketching" and the code will be written using $\mathrm{C}++$ programming language. The respective sketch must be accurately called for other electronic tools or sensors linked with the Arduino board via its pin. All the instructions and logical behaviors of supportive electronic tools or sensors will be created in this sketching step. Operational functions of the entire circuit will be depending on the sketched program.

Compiling Process: When it comes to the end of the coding process, the user can check it for errors before make it active by run compiling command. If any errors occurred in 
programming code or hardware connections, compiling process will be highlighted those errors. I

Uploading: After successfully passes the compiling process, the sketch is ready for uploading. The prepared sketch can be uploaded to the connected Arduino board through IDE software interface. Generally Ardunio board will be connected to the computer via USB port.

Power Management: Arduino board can be connected to any computer interface via USB ports and the power for its functionality will be controlled through the USB connection. If the Arduino board is going to be installed in another place, the user must be concerned about the power source for Arduino.

Feedback Monitoring: Arduino IDE interface has got a inbuilt serial monitor command which will enables the user to capture the real time working feedbacks of the Arduino board. Variable changing, value measuring, timely changes of outputs and inputs can be taken as examples for serial monitoring.

Figure 2: Process flow chart

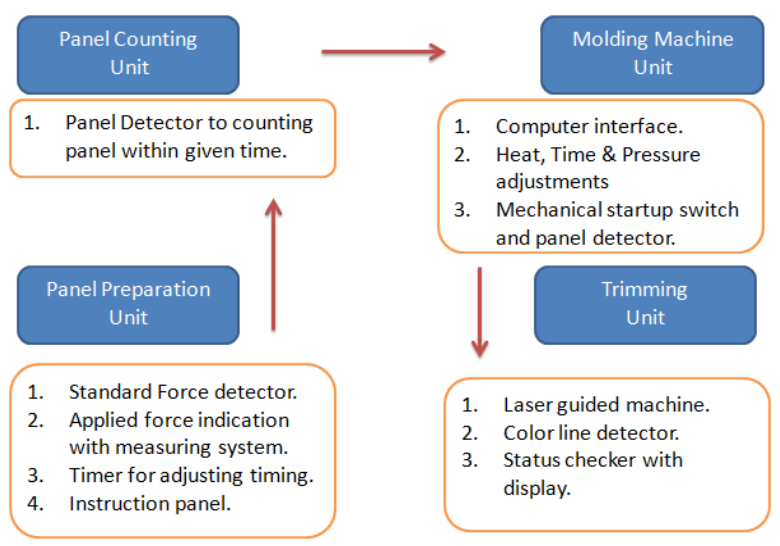

\section{BUILD UP THE ARDUINO DEVICES.}

\section{A. Arduino device for Panel Preparation}

Panel preparation is the first operation in dancing module. During the initial training, the newly recruited employee must be undergone a training which was developed to build up the hand skills of the employees. The trainee practiced the panel cleaning procedure with specific hand drill which is three times from left to right and three times from top to bottom cleaning of the panel. During this process the appropriate pressure must be applied on the panel in order to ensure the panel is cleaning deeply and accurately. In the normal practice both the trainer and the trainee do not have any method to evaluate the pressure applied on the panel. Due to this issue it is obviously took more time to complete this training.

In Arduino the specific device has been proposed for panel cleaning operation. Force sensor of $10 \mathrm{~N}$ was used for this device in order to measure the applied force on the panel. The trainee should be applied the expected pressure on the panel and then only the LED light indicators will illuminate. The required pressure can be uploaded to the Arduino board by the trainer during the sketch process. The brightness of the LED lines will be increased with the applied pressure. If the pressure is very low, the lights will be illuminated with a less brightness. The trainer can connect his computer to the device and read the Serial Monitor and watch the average pressure applied by the user in each and every time. He can correct him by evaluating that. The trainee will be practiced the procedure very quick with entertaining the training process.

Another important feature is the timer. The timer has given the time frame for trainee to clean. He must be cleaned the given panel with the required force applied on it, with in an allocated time. He can observe the timer and improve his timing subsequently. The timing capacity can be adjusted by the trainer in charge. After use the device for one user the timer can reset for the second user. Trainer can get evaluation report in physical format using Serial Monitor data recording in the Arduino IDE interface.

Figure 3: Panel preparation device

The next sub attachment for this device is the panel

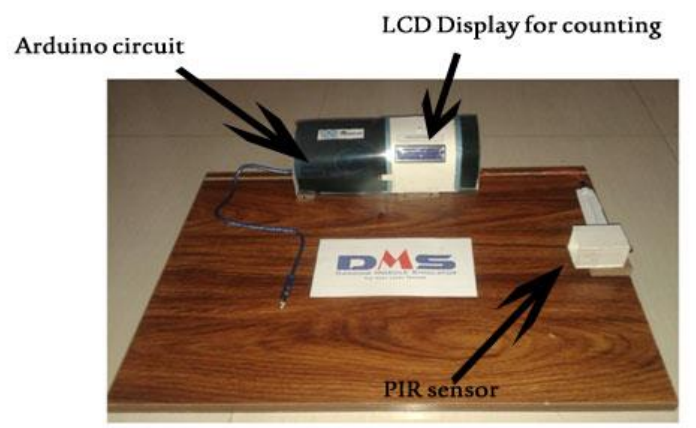

Figure 5: Panel counting device

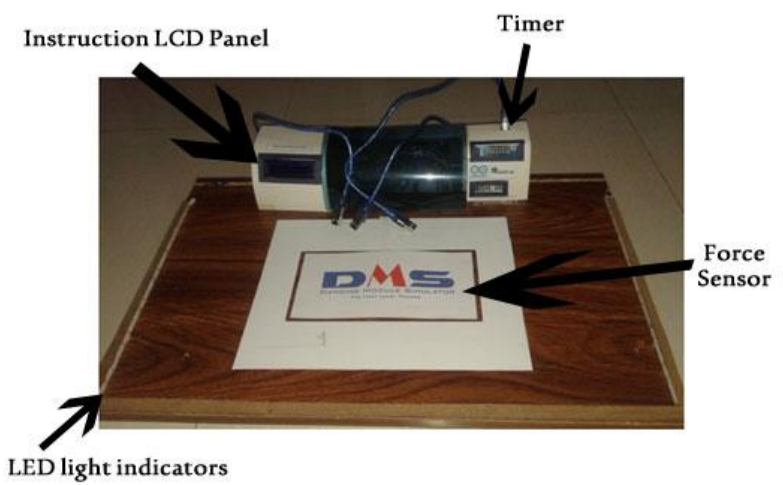

counting Arduino device. This interface has been created a counting feature of the cleaned panel by the trainee. To get a standard evaluation of how many panels he has cleaned during the given time, this device is very important to use as a training aid. Each and every time the trainer starts his first training he can adjust these two devices simultaneously.

The panel counting attachment was built using Arduino UNO board with Passive Infrared Sensor (PIR). This sensor is detecting the movements by breaking the IR ray emitting from it. When the trainee's hand cut off the Uni-directional IR 
beam, the Arduino interface will begin to count the movement with given delay timing. This device was placed on the right side of the panel cleaning device as it will create easy access to the user and the trainer.

Figure 6: Panel Preparation and Counting Diagram

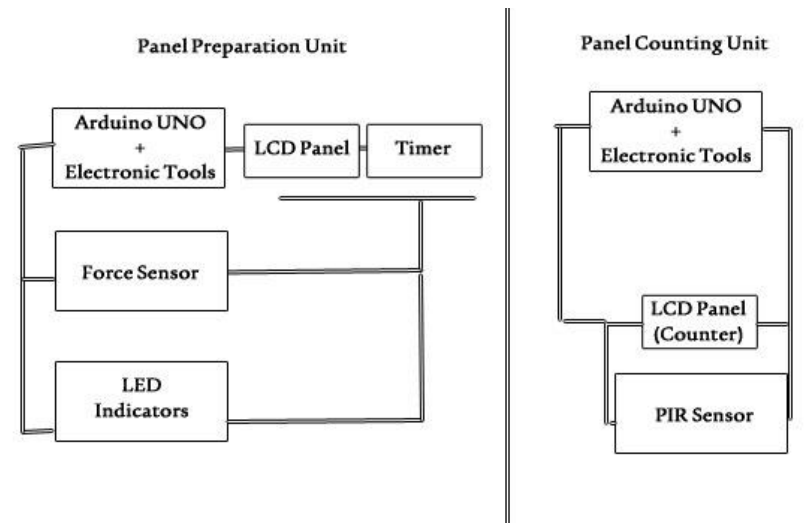

\section{B. Molding operation training}

The molding operation training of the simulator is the second and the only part which includes computer interface. Molding operation will be taught to trainer by using a virtual molding machine. Graphical interface of the simulator was designed exactly with the features of the real molding machine. The training process currently in use for molding operation machine is challengeable as most of the trainees reported injuries as the machine deals with the high temperature values as 180-230 degrees of Celsius. Due to this practical limitation the molding operation practice will be taken more days. The critical level of the actual machine training is very high. Virtual machine training will be provided a better room for trainee to develop his understanding about the machine and its functionality.

The virtual molding machine was developed by using Asp.Net interface. Graphical features and animations were created by using Adobe Flash CS5. Action Script 3.0 programming has been used as secondary programming language to generate few animation movements. Respective virtual molding machine is proposed to be installed in the simulator room. LCD display can be used to run the virtual molding machine program. The trainee expected to learn below functions of the molding machine.

1. Temperature adjustment operation.

2. Air pressure adjustment operation.

3. Timing observation training.

4. Parts of the mold identification.
Figure 8: Virtual molding machine
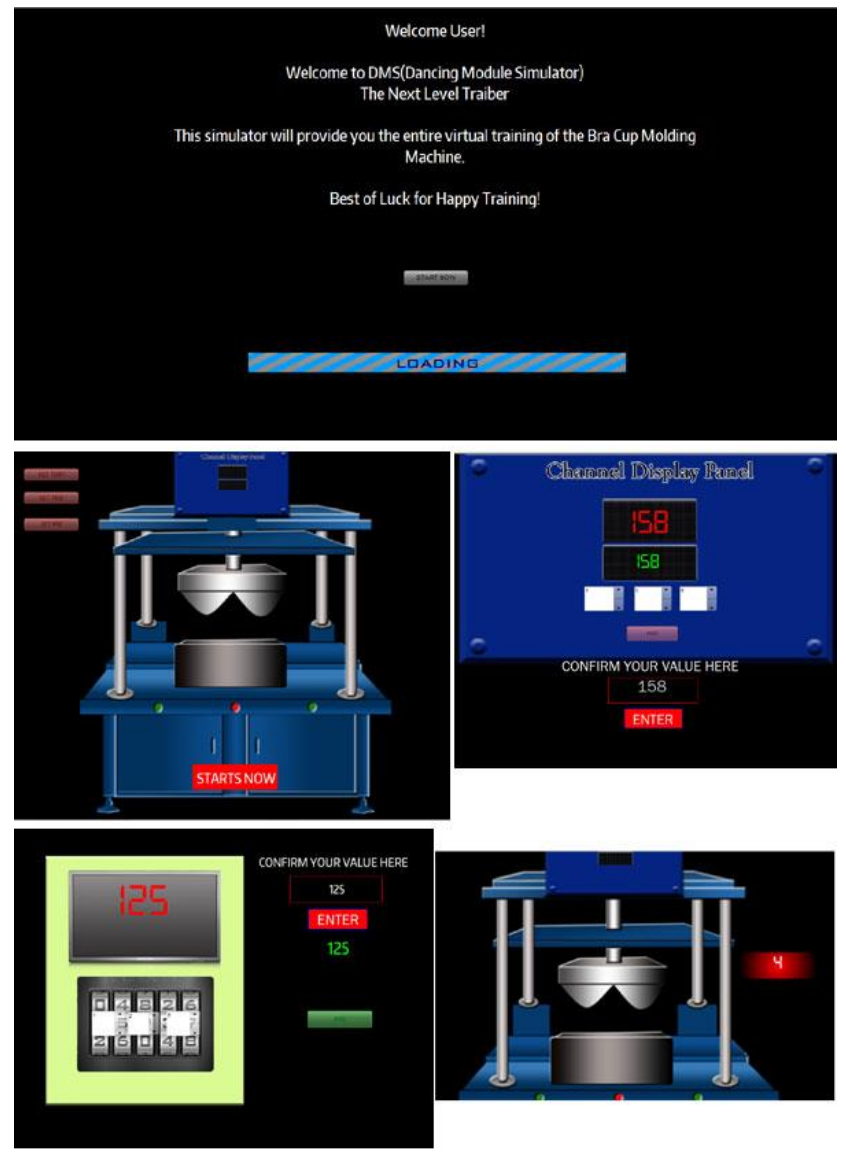

The virtual molding machine consists of user profile login system which enables trainees to create his own profile in the training system. He can access and view his history records in future which recorded in the system data base. This will create an opportunity to user to identify his capabilities and improve his self if needed. This virtual trainer will reduce the risk of handling the actual molding machine. Introduction on molding operation, temperature adjustment, air adjustment and timing controlling are main expectation to be achieved by using this virtual molding machine.

\section{Trimming operation training}

Trimming is the most important part of the dancing module as it will require high level of skills in hand movements. Production level employees are identified as highly developed skilful workers for trimming operation. This movement of the dancing module will be highly affected for the Small Minute Value (SMV). Industrial engineers of the company are always considering about the said value and its changes during the production. Develop new trainees into the standard level will be helped a lot to production department as they can allocate new workers soon to the production lines. The trimming operation training of the simulator was designed with the Arduino interface. It has been focused mainly on the trimming through the line of the molded bra cup. In real scenario the worker must trim the molded bra cup by following the engrave lines. Small mistake trim the inner side of the bra cup and it will cost huge amount of loss for the company. Hand 
movement skills of the trainee must be developed up to the level of follow a line accurately for with the trimming blade. In this step, the Arduino technology was used with color detecting sensor. The main circuit has designed by linked a colour sensor module with the Arduino UNO interface. A laser pointer was attached above the colour detector to guide the bra cup on exact line.

The trainer will be given a white fabric which painted dark black lines similar to the original molded bra cup. The colour detector was given the command to detect the black colour only. So the trainee must be careful to maintain his concern on the black lines on the sample white fabric. If the user has move out from the black lines feeding, the system will be notified the user by displaying an error message "Your trimming line is out! Try again". Also the number of line out movements will be calculated by the system and it enables the trainer to evaluate the trainee. Timer also attached to this system to count the time duration will be taken by the trainee. Finally the trainer can get data of the trainee's trimming operation by referring the Serial Monitor data records of the Arduino IDE software.

Figure 9: Trimming operation training device

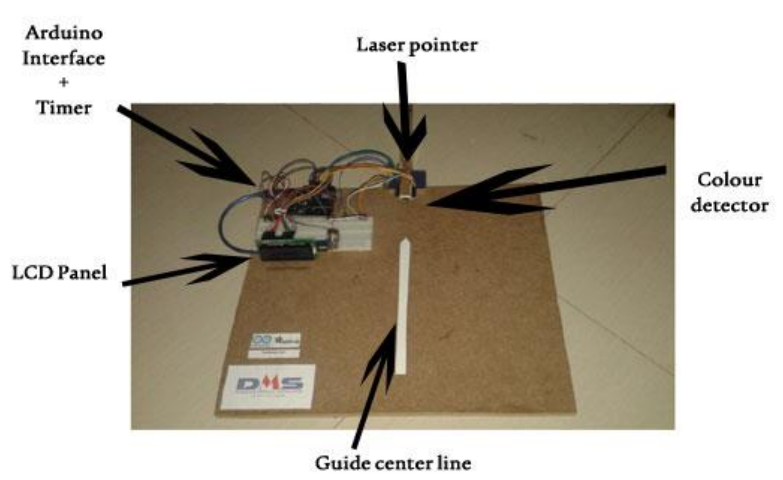

\section{PROGRESS ANALYSIS}

\section{A. Results experienced from the proposed simulator}

Proposed Dancing Module Simulator (DMS) has been tested for two new intakes of workers who joined with the company. These two groups were taken as the sample for the two trials. There were 23 members in group-1 and 20 members in group-2. Only 12 members from group-1 were female candidates and 8 members from group-2. All of the trainees were allocated to the simulator project after the initial recruitment process of the company. According to the general training plan which used for earlier batches, group-1 has been allocated 62 days for training while group-2 received 60 days. Both two groups were given the time frame for simulator training before they have started the sessions.

Table 4: Estimated time allocation for group-1

\begin{tabular}{|l|l|}
\hline \multicolumn{1}{|c|}{ Event } & \multicolumn{1}{|c|}{ Estimated days } \\
\hline 1. Introduction program & 1 days $(8 \mathrm{HRS})$ \\
\hline 2. Panel preparation training & 7 days $(56 \mathrm{HRS})$ \\
\hline 3. Molding machine training & 8 days $(64 \mathrm{HRS})$ \\
\hline 4. Trimming training & 10 days $(80 \mathrm{HRS})$ \\
\hline 5. Final training with actual machines & 5 days $(40 \mathrm{HRS})$ \\
\hline Total days & 31 Days \\
\hline
\end{tabular}

Table 5: Estimated time allocation for group-2

\begin{tabular}{|l|l|}
\hline \multicolumn{1}{|c|}{ Event } & \multicolumn{1}{c|}{ Estimated days } \\
\hline 1. Introduction program & 1 days $(8 \mathrm{HRS})$ \\
\hline 2. Panel preparation training & 6 days $(56 \mathrm{HRS})$ \\
\hline 3. Molding machine training & 7 days $(64 \mathrm{HRS})$ \\
\hline 4. Trimming training & 10 days $(80 \mathrm{HRS})$ \\
\hline 5. Final training with actual machines & 5 days $(40 \mathrm{HRS})$ \\
\hline Total days & 29 Days \\
\hline
\end{tabular}

Two simulator modules were used for the training of two groups. Each groups were divided into two teams again and each person was received the training in rounding basis. During the final training session users were able to get the actual scenario training with real machines and conditions. The sessions were planned to finish after evaluate each member's results and define the skill level of them as ready or not ready for the production lines. Employees who were not performed well in the simulator training will be forwarded to the general training. The results have been recorded as follows.

Table 6: Recorded results

\begin{tabular}{|l|c|c|c|c|}
\hline \multicolumn{5}{|c|}{ Group-1 } \\
\hline Event & $\begin{array}{l}\text { Days } \\
\text { taken }\end{array}$ & $\begin{array}{l}\text { Skill } \\
\text { level }>80 \%\end{array}$ & $\begin{array}{l}\text { Skill } \\
\text { level }<80 \%\end{array}$ & Percentage \\
\hline 1 & 1 & 19 & 4 & $83 \%$ \\
\hline 2 & 5 & 19 & 4 & $83 \%$ \\
\hline 3 & 5 & 18 & 5 & $78 \%$ \\
\hline 4 & 7 & 19 & 4 & $83 \%$ \\
\hline 5 & 3 & 19 & 3 & $83 \%$ \\
\hline Total & $\mathbf{2 1}$ days & \multicolumn{5}{|c|}{ Group-2 } \\
\hline Event & $\begin{array}{l}\text { Days } \\
\text { taken }\end{array}$ & $\begin{array}{l}\text { Skill } \\
\text { level }>80 \%\end{array}$ & $\begin{array}{l}\text { Skill } \\
\text { level <80\% }\end{array}$ \\
\hline 1 & 1 & 18 & 2 & $90 \%$ \\
\hline 2 & 5 & 19 & 1 & $95 \%$ \\
\hline 3 & 4 & 18 & 2 & $90 \%$ \\
\hline 4 & 7 & 19 & 1 & $95 \%$ \\
\hline 5 & 3 & 19 & 1 & $95 \%$ \\
\hline Total & $\mathbf{2 0}$ days & \multicolumn{5}{l}{} \\
\hline
\end{tabular}

According to the results recorded from both groups only five people were identified as trainees who need further trainings. Those five people were recorded from group-1 in Event-3 (molding machine virtual training). Majority of trainees $(88 \%)$ were passed the DMS simulator training successfully and forwarded to the production lines after they have completed final training with actual machines.

\section{CONCLUSION}

\section{A. Success rate of Dancing Module Simulator (DMS)}

According to the results recorded above, the success rate of simulator training is more than $85 \%$. It has reduced the allocated time duration for the training session from 62 days to 21 days averagely. This time saving was guided the process to save financial resources allocated for a training session.

\section{B. Benefits}

Table 7: Benefits of DMS

\begin{tabular}{l|l}
\hline $\begin{array}{l}\text { Traditional training } \\
\text { program }\end{array}$ & DMS training program \\
\hline
\end{tabular}




\begin{tabular}{|l|l|}
\hline 62 days & 21 days only \\
\hline $\begin{array}{l}90 \% \text { forwarded to the } \\
\text { production lines }\end{array}$ & $\begin{array}{l}88 \% \text { forwarded to the } \\
\text { production lines }\end{array}$ \\
\hline 3850 LKR per head cost & Approximate 1675 LKR \\
\hline More resources needed & Less resources needed \\
\hline High power consuming & Less power consuming \\
\hline Less trainee interest & High trainee interest \\
\hline High space utility & Less space utility \\
\hline Less return on investment & High return on investment \\
\hline
\end{tabular}

\section{Future developments}

1. Future developments for the respective DMS system can be designed in order to enhance the user interaction and smoothness of the functions. The simulator should be more digitized and access for analysis trainee's statistics should be developed more.

2. Virtual molding operation system can be developed further by using advanced language such as Java programming.

3. The simulator can be upgraded into a mobile application which enables the trainer to evaluate his performances in real time and offline.

4. The company's HR system can be attached to the performance analysis of the system in order to maintain an employee's performance analysis system.

\section{ACKNOWLEDGMENT}

In conducting this research we have received magnificent help from many quarters, which we like to put on record with great gratitude and great pleasure.

This research was supported by Faculty of Engineering of Kotelawala Defence University. First and foremost we would gratefully remind Senior lecturer Mr. Rangajeewa who gave us the guidance throughout this project with insight and expertise that greatly assisted the research as the project supervisor to share his knowledge without any hesitation.

We offer our sincere gratitude to Mr. Dissanayake of Department of Aeronautical Engineering in Kotelawala Defence University for directing us in every possible ways to make this project a success and for their advices and assistance in keeping our progress on schedule. Also the lessons we learnt during our graduate period was a major benefit in completing the research successfully.
Finally this research made possible through the help and support from family members who provide the greatest support and their encouragement throughout our studies.

\section{REFERENCES}

1. Dr Amandeep, Dr Aneet, \& Shipra. (2018). Training Practices in Large and Medium Textile and Apparel Industries of. IOSR Journal of Business and Management (IOSR-JBM), 20(2), 59-65.

2. Behr, O. (2018, February). Fashion 4.0 - Digital Innovation in the Fashion Industry. JOURNAL OF TECHNOLOGY AND INNOVATION MANAGEMENT, 2(1), 1-9. doi:2018

3. Caro, P. W. (1997). Factors Influencing Simulator Training Effectiveness in the. HumPro, 07(2), 77-83.

4. Gallardo, D. Julia, \& S. Turtan. (2008). A tangible programming language for creative exploration. 3rd IEEE International Workshop (pp. 89-92). IEEE.

5. Guevara, G. (2017, June 12). Popular Recent Comments Tags Sound Localization using Arduino Wii Nunchuk Controlled Model Train using Arduino New Filterable Project Old Simple Project. Retrieved from Academia: https://www.academia.edu/37867688/ArduinoBased_Speed_Limit_Detector_with_SMS_Support_Its_Appli cability_and_Usability_to_Traffic_Management_Unit_ 6. Harrilal, B. (2017). Arduino Programming Language. Delhi.

7. Hearle, C. (2016). Skills, Employment and Productivity in the Garments and Construction Sectors in. ECONOMIC AND PRIVATE SECTOR - PROFESSIONAL EVIDENCE AND APPLIED KNOWLEDGE SERVICES, 12-20.

8. Louis, L. (2016). WORKING PRINCIPLE OF ARDUINO AND USING IT. International Journal of Control, Automation, Communication and Systems (IJCACS), 1(2), 21-29.

9. ORGANTINI, G. (2016). SCIENTIFIC ARDUINO PROGRAMMING. Arduino Open-Source Community, 2330 .

10. Vega, N. G. (2017). Factors Affecting Simulatortraining. JYVÄSKYLÄ STUDIES IN EDUCATION, PSYCHOLOGY AND SOCIAL RESEARCH, 09(2), 17-23.

11. Wright, B. (2018, May 04). How to tackle the apparel industry's digital skills gap? Retrieved from Just-Style2018: https://www.just-style.com/analysis/how-to-tackle-theapparel-industrys-digital-skills-gap_id132471.aspx 